\title{
Considerations of temperature in the context of the persistence classification in the EU
}

Michael Matthies ${ }^{1 *}$ and Sabine Beulke ${ }^{2}$

\begin{abstract}
Simulation degradation studies for industrial chemicals, biocidal products and plant protection products are required in the EU to estimate half-lives in soil, water and sediment for the comparison to persistence criteria for hazard (P/vP) assessment, and for use in exposure assessments. There is a discrepancy between European regulatory approaches regarding the temperature at which degradation half-lives should be (1) measured in simulation degradation testing of environmental compartments, and (2) compared to the P/VP criteria. In this paper, an opinion is provided on the options for the experimental temperature and extrapolation to other conditions. A review of the historical development of persistence criteria did not give conclusive evidence of the temperature at which the half-lives that underpin the P-criteria were measured, but room temperature is likely. Half-lives measured at $20^{\circ} \mathrm{C}$ are in line with the intentions of some international agreements, but in the $\mathrm{EU}$ there is a continued political debate regarding the relevant temperature for comparison with persistence criteria. Measuring degradation at $20^{\circ} \mathrm{C}$ has the advantage that metabolites/transformation products can be identified with greater accuracy, and that kinetic fits to determine half-lives for parent compounds and metabolites carry less uncertainty. Extrapolation of half-lives to lower temperatures is possible for assessing environmental exposure, but the uncertainty of the persistence classification is smaller when measured half-lives are used for direct comparison with P/VP criteria, without extrapolation. Model simulations demonstrate the pattern of concentrations that can be expected for realistic worst case climate scenarios in the EU based on the half-life of 120 days in soil at $20^{\circ} \mathrm{C}$ and of 40 days in water at $20^{\circ} \mathrm{C}$, and their temporal and spatial variability.
\end{abstract}

Keywords: PBT assessment, Exposure assessment, Environmental temperature, Hazard, Degradation simulation testing, Persistence criteria, Arrhenius equation, Temperature normalisation

\section{Background}

Classification of a chemical as being persistent $(\mathrm{P})$, bioaccumulative $(\mathrm{B})$ and toxic $(\mathrm{T})$ or very persistent $(\mathrm{vP})$ and very bioaccumulative $(\mathrm{vB})$ is an integral part of the chemical legislation in the European Union (EU). PBT/ $\mathrm{vPvB}$ substances can give rise to specific concerns due to their potential to accumulate in parts of the environment, which is in practice difficult to reverse and the effects of such accumulation are unpredictable in the long-term [15]. Criteria for PBT/vPvB hazard assessment

\footnotetext{
*Correspondence: matthies@uos.de

${ }^{1}$ Institute of Environmental Systems Research (USF), University of Osnabrück, 49069 Osnabrück, Germany

Full list of author information is available at the end of the article
}

are laid down in the European regulation for industrial chemicals registered under REACH [23], biocidal products [25], plant protection products (PPP) [24], and veterinary medicines [21]. These criteria are identical across European regulatory frameworks but the consequences are quite different [36]. Guidance for $\mathrm{PBT} / \mathrm{vPvB}$ assessment of industrial chemicals and biocidal products has been provided since 2003 in Technical Guidance Documents and their revisions [12, 13, 15, 17, 26]. Although chlorinated PPPs have been amongst the first acknowledged POPs (persistent organic pollutants), PBT/vPvB assessment of PPP was only introduced in 2009 with the new regulation EC 1107/2009 [24], but no guidance was provided on how to conduct a $\mathrm{PBT} / \mathrm{vPvB}$ assessment [46]. A working document was issued by DG [10] which 
laid down the evidence needed to identify POP, PBT and $\mathrm{vPvB}$ properties for PPPs.

For persistence classification in the EU, degradation halflife criteria have been defined for fresh, estuarine and marine waters and sediments and for soil (Table 1). However, it is not clear what the relevant conditions are for the half-lives to be compared with persistence criteria. In particular, temperature has a great influence on the degradation half-lives in water, sediment and soil since (bio) chemical reactions are temperature dependent. For PPP, a reference temperature of $20^{\circ} \mathrm{C}$ is recommended and degradation half-lives ${ }^{1}$ should be normalised to this temperature if the study has been undertaken at a different temperature [10]. On the other hand, a temperature of $12{ }^{\circ} \mathrm{C}$ as a standard environmental characteristic and $9{ }^{\circ} \mathrm{C}$ for abiotic marine degradation has been proposed for industrial chemicals and biocidal products $[15,16,26]$. Moreover, the temperature at which chemicals should be tested in laboratory simulation studies is still a matter of discussion and is related to the method of extrapolation to other temperatures. Thus, there is a discrepancy between the various European regulatory approaches regarding the temperature at which degradation half-lives should be [1] tested in simulating degradation testing of environmental compartments, and [2] compared to the $\mathrm{P} / \mathrm{vP}$ criteria of Table 1.

The objectives of the paper are to provide an opinion on the following:

- The temperature at which the half-life should be measured for $\mathrm{P} / \mathrm{vP}$ assessment.

- How the half-life should be derived (measure at $20{ }^{\circ} \mathrm{C}$ or measure at $12{ }^{\circ} \mathrm{C}$ and then extrapolate to $20^{\circ} \mathrm{C}$ ).

- How the extrapolation should be undertaken and under which conditions it is valid.

\section{Environmental exposure and hazard (PBT/vPvB) assessment in the EU \\ Exposure assessment}

Degradation half-lives in water, sediment and soil are not only required as hazard properties in $\mathrm{PBT} / \mathrm{vPvB}$ assessment, but also as input data for environmental and indirect human exposure and risk assessment. For this purpose, specific exposure scenarios and environmental transport and fate models have been developed and used for the calculation of predicted environmental concentrations (PECs) in air, water, soil and sediment. The environmental risk is characterised by dividing these PECs by appropriate PNECs (predicted no-effect concentrations)

\footnotetext{
${ }^{1}$ The time for $50 \%$ decline in the initial mass by degradation and/or other loss mechanisms is referred to in the literature as DT50, DegT50, half-life or $t^{1 / 2}$. Throughout this article, half-life is used and this is abbreviated as $t^{1 / 2}$.
}

Table 1 Criteria for the classification as P or vP [23]

\begin{tabular}{|c|c|}
\hline Criteria for persistence (P) & $\begin{array}{l}\text { Criteria for very } \\
\text { persistent (vP) }\end{array}$ \\
\hline $\begin{array}{l}\text { Marine water: } t 1 / 2>60 \text { days } \\
\text { Fresh and estuarine water: } \\
t 1 / 2>40 \text { days } \\
\text { Marine sediment: } t^{1 / 2}>180 \text { days } \\
\text { Fresh and estuarine sediment: } t^{1 / 2}>120 \text { days } \\
\text { Soil: } t 112>120 \text { days }\end{array}$ & $\begin{array}{l}\text { Water: } t^{1} / 2>60 \text { days } \\
\text { Sediment: } \\
\quad t^{1} 1 / 2>180 \text { days } \\
\text { Soil: } t^{1} 1 / 2>180 \text { days }\end{array}$ \\
\hline
\end{tabular}

or by calculating Toxicity Exposure Ratios. For industrial chemicals and biocides, the Guidance on Information Requirements and Chemical Safety Chapter R.16 [14] details the methodology of environmental exposure estimation and the role of degradation half-lives. It is obvious that PECs should be calculated at the relevant temperature for the exposure models employed. A reference temperature of $12^{\circ} \mathrm{C}$ is defined as average outdoor temperature in Europe and $9{ }^{\circ} \mathrm{C}$ as average temperature of marine waters.

However, degradation has only a limited impact on calculated PECs of industrial chemical and biocidal products. Degradation rate constants are input parameters for the calculation of $\mathrm{PEC}_{\text {regional }}$ and $\mathrm{PEC}_{\text {local }}$ for soil, but not for sediment and surface water, which is the receiving compartment for almost all industrial chemicals and biocides. Moreover, half-lives for biodegradation in surface water based on results of screening tests on biodegradability or (Q)SAR calculations do not need to be corrected for different environmental temperatures. Thus, temperature correction of degradation half-lives has only a minor influence on exposure and risk assessment for industrial chemicals and biocides.

For active substances of PPP, approved versions of FOCUS simulation models and FOCUS scenarios are used to calculate the concentrations in groundwater [27] and surface water [29] in the EU review process [24]. Degradation half-lives for soil, surface water and sediment are used as input parameters and these are adjusted to half-lives at the actual temperature on each day of the simulation period for the various European scenarios. Annual average temperatures range from $8{ }^{\circ} \mathrm{C}$ in northern to $18{ }^{\circ} \mathrm{C}$ in southern countries [27, 29]. Thus, the variability across the European climate zones is explicitly taken into account in the environmental exposure assessment, which makes an average European outdoor temperature obsolete for PPP. Regional distribution models are not part of exposure assessment of PPP.

\section{Hazard assessment}

In chemical hazard assessment, intrinsic substance properties are directly compared to pre-defined criteria without any of the processing that is done in exposure 
models. These criteria are regarded as independent of the intended use, emission volume and mode of entry into the environment. Thus, there is a fundamental difference in environmental exposure and $\mathrm{PBT} / \mathrm{vPvB}$ hazard assessment: (1) in environmental exposure assessment, concentrations are predicted by taking account of simultaneous processes of transport, distribution and degradation in and between representative environmental compartments at conditions relevant for the EU [15]; (2) in PBT/vPvB assessment, hazardous substance properties are compared to numerical and narrative criteria, which are based upon available data for reference chemicals, derived under laboratory conditions, and consensus-based policy discussions [1]. Thus, the scientific background as well as the political intentions and assumptions under which the criteria have been derived are of utmost significance.

\section{Reference temperature for persistence criteria in $\mathrm{P} /$ vP assessment}

A brief summary of the historical development of persistence criteria is provided with particular consideration of temperature.

\section{Non-EU regulations and international agreements}

Development of criteria for classification of persistent toxic substances goes back to the 70s of the last century. They evolved over the last decades due to the diversification of the protection aims under various national regulatory frameworks and international agreements [34]. Japan was the first nation regulating PCBs and other chloro-organic compounds by assessing their $\mathrm{P}, \mathrm{B}$, and $\mathrm{T}$ properties [35]. However, they did not define criteria for a formal assessment process. Canada and the USA recognised the need for elimination of persistent toxic substances from the Great Lakes and introduced the concept of half-life of a substance in water as a measure (criterion) for persistence [31, 50]: "Half-life means the time required for the concentration of a substance to diminish to one-half of its original value in a lake or water body". They also defined a numerical value for the persistence criterion: "Persistent toxic substance means any toxic substance with a half-life in water of greater than eight weeks" [31, 50]. With the beginning of the 90s, various international commissions and North-American national institutions developed further the concept of environmental half-lives as persistence criteria and extended it to other environmental compartments (air, soil, sediment, ground water). An ad hoc science group of Environment Canada [22] reviewed degradation half-lives of a set of critical substances, mainly hydrophobic neutral organic compounds, such as PCBs, PAHs, PCDD/Fs. Scientific judgement was used to assign numerical values (half-lives) of 6 months in water and soil and 1 year in sediment, respectively, which became legally binding with the Canadian Environmental Protection Act [8]. The different half-lives reflect the persistence data available for the set of neutral hydrophobic reference chemicals, against which a chemical is to be compared. The group stated that "...under Canadian climate conditions 6 months is a reasonable window of time in which soil temperature and moisture favour biodegradation of many substances".

With the evidence of long-range transboundary transport (LRT) of chemicals, broader international activities were launched for regulating persistent organic pollutants (POPs) $[47,49]$. The specified half-life in water of 60 days was not based on new scientific findings or different environmental temperatures to be considered but was a compromise with a simultaneous decision for a bioconcentration factor (BCF) of 5000. The UNEP Criteria Expert group on POPs [48] stressed the need for the development and improvement of relevant test methods and recommended that the International Standards Organization (ISO) and the Organisation for Economic Cooperation and Development (OECD) undertook efforts to ensure that such needs concerning new and improved test methods were better met. Up to this point, temperature has not been explicitly considered for screening of chemicals based on their persistence according to the criteria in Annex D of the Stockholm Convention [49].

USEPA [51, 53] reviewed persistence criteria defined in various international agreements and national regulations and specified a lower boundary of 60 days for moderate action and an upper boundary of 180 days for high action without consideration of specific environmental compartments and conditions. A half-life of 60 days was chosen because the initial concentration of a released chemical drops to approximately $1 \%$ within 1 year, i.e. six half-lives. Soil biodegradation is tested at $22 \pm 2{ }^{\circ} \mathrm{C}$ [52].

An international expert group at the SETAC Pellston workshop "Science-Based Guidance and Framework for the Evaluation and Identification of PBTs and POPs" stated that "It is reasonable to assume that persistence criteria, defined according to the reference chemical approach, are related to available half-life data for known POPs. Because these half-lives are likely to have been derived under laboratory conditions, these are the conditions for which the comparison should take place. According to the reference chemical approach, temperature correction, therefore, does not seem justified" [7].

\section{EU regulations}

The Oslo Paris Convention (OSPAR) was the first European convention dealing with persistent substances in 
the environment [40, 41]. A half-life of 50 days in marine waters was defined as the only persistence criterion without further specification of the test methods and conditions, e.g. temperature. Around the year 2000, several papers and statements dealt with the temperature relevant for European climate conditions. The Swedish Committee on New Guidelines on Chemicals Policy [9] proposed that "a substance is regarded as unacceptably persistent if its half-life is longer than 8 weeks in a simulation test at $20{ }^{\circ} \mathrm{C}$ ". This half-life corresponds to a halflife of 1 year in the northern European climate (average annual temperature of $5{ }^{\circ} \mathrm{C}$ ) and takes into account unfavourable degradation conditions. Sinkkonnen and Paassivirta [45] suggested degradation half-times for POPs as input parameters to the Baltic Sea model assuming an annual average temperature of $7{ }^{\circ} \mathrm{C}$. Beyer et al. [5] could demonstrate that the LRT potential can monotonically increase or decrease with increasing temperature, or it can have a maximum in the temperature range between 5 and $30^{\circ} \mathrm{C}$.

The Technical Guidance Document (TGD) on Risk Assessment [26] added a new chapter on marine risk assessment, which also contains a subchapter on PBT assessment. Consequently, only criteria for water systems (fresh and marine waters and sediments) were defined (Table 1) in 2003, but not for soil. The numerical values for marine water (60 days) and sediment (180 days) as well as those for $\mathrm{vP}$ assessment are identical with those of international agreements, but for those fresh water (40 days) and fresh water sediment (120 days) are smaller. European outdoor temperature was not taken into consideration when defining the criteria.

$\mathrm{PBT} / \mathrm{vPvB}$ assessment became legally binding with the release of REACH [23], which laid down the persistence criteria from the TGD [26] plus a half-life in soil of 120 days, which is shorter than in the international agreements. Again, the relevant temperature (and other environmental conditions) for testing persistence was not defined in the regulation. In the first version of the Guidance in Information and Chemical Safety Assessment Chapter R.11 [12], nothing is said on the relevant temperature for persistence testing. In version 2.0 of the Guidance Chapter R.11 [15], one sentence relates to temperature: "Please note that since its 32nd meeting the Member State Committee has started to require new simulation degradation studies to be carried out around neutral $\mathrm{pH}$ values and at $12{ }^{\circ} \mathrm{C}$, which is understood as the mean temperature of European surface waters". The draft version 4.0 of the Guidance Chapter R.7b Endpoint specific guidance [16] states that "New simulation studies should be conducted at environmentally relevant temperatures namely at $12{ }^{\circ} \mathrm{C}$ as this is seen as the average surface water temperature for the European Union $\left(9{ }^{\circ} \mathrm{C}\right.$ for sea water). If information on degradation half-life is already available from existing simulation degradation tests performed at a higher temperature, they should be normalised to a half-life corresponding to $12{ }^{\circ} \mathrm{C}$ by using the Arrhenius equation". A generic activation energy of $65.4 \mathrm{~kJ} \mathrm{~mol}^{-1}$ is proposed which has been derived by EFSA [19] (see below). The draft version 3.0 of the Guidance Chapter R.11 PBT/vPvB assessment [17] refers to this statement. Simulation degradation studies should be performed according to the OECD guidelines no. 307 for aerobic degradation in soil [37], no. 308 for anaerobic and aerobic transformation in water and sediment [38] and no. 309 for aerobic mineralisation in surface water [39]. However, Honti and Fenner [30] concluded that available OECD 308 data are insufficient to derive persistence indicators that had both acceptable robustness and uncertainty. Rauert et al. [42] proposed “...normalising DegT50 values to $12{ }^{\circ} \mathrm{C}$ because this temperature is established or suggested under the majority of frameworks (i.e. Biocides Regulation, REACH and medicinal products Directives)". However, the guidance for $\mathrm{PBT} / \mathrm{vPvB}$ assessment is the same for the three mentioned frameworks. For PPP, DG [10] stated in its Working Document on "Evidence needed to identify POP, PBT and $\mathrm{vPvB}$ Properties for Pesticides": "Laboratory studies: DT50 values should be normalised to a temperature of $20^{\circ} \mathrm{C}$, as this is the current practice in recent assessments of soil degradation rates of active substances". This Working Document has been applied for the initial establishment of the list of candidates for substitution [11] as required in Article 80 [7] of Regulation (EC) No 1107/2009 [24], i.e. half-lives at $20{ }^{\circ} \mathrm{C}$ have been considered when the list was compiled.

\section{QSAR approaches}

Simulation studies are preferred for the determination of biodegradation half-lives. However, for the vast majority of industrial chemicals no data are available from simulation studies. Thus, information from test on ready and inherent biodegradability as well as from (Q)SAR methods (BIOWIN from EPI Suite, [54]) has been recommended for screening substances as being potentially persistent [15]. The screening criteria, laid down in Table R.11-4, are not legally binding whereas the (definitive) P/ vP criteria are (see Table 1). Testing on biodegradability is conducted at room temperature and not temperature corrected. BIOWIN generates biodegradation half-lives in water and assigns them to five classes representing half-lives from hours to years. The half-life in water is multiplied by factors of 2 and 9 to obtain a half-life in soil and sediment, respectively. BIOWIN models for primary and ultimate degradation have been developed from expert surveys [6]. Arnot et al. [3] calibrated the models to empirical aerobic environmental half-life data from 40 
selected "training set" chemicals and evaluated the outcome of this calibration with environmental aerobic biodegradation data of a set of 115 chemicals. Although it is not explicitly stated at which temperature biodegradation half-lives were determined, room temperature for laboratory and summer temperature for field measurements can be assumed. Regression analysis was undertaken to identify statistical relationships between biodegradability and basic properties. As the QSAR models were trained using data on biodegradation half-lives at room temperature, any predictions will also refer to this temperature. Temperature correction of the results of biodegradability testing and BIOWIN calculations is not required for screening information [15].

\section{Overall persistence}

Persistence criteria are based on the hazardous properties of hydrophobic neutral reference chemicals. Under this approach, it is assumed that the objective of the $\mathrm{P}$ assessment is to avoid chemicals similar to known PBTs such as PCBs. These known PBTs have different half-lives in different media. Degradation in water is assumed to be faster than in soil and sediment. An alternative approach, called management approach $[7,43]$ is to attempt to limit the overall residence time of a chemical in the environment as the goal of the assessment scheme. The overall residence time or the reciprocal overall persistence, $P_{\mathrm{ov}}$, can be calculated by a multimedia model, which takes into account environmental degradation as well as distribution [33, 44]. The objective is to control the presence of chemicals in the environment and not to compare halflives against a pre-defined set of media-specific criteria. Thus, average environmental temperature could be considered in multimedia modelling as it is done for calculation of $\mathrm{PEC}_{\text {regional }}[15]$.

\section{Accumulation in the environment}

The main concern underlying the persistence assessment is resistance to degradation processes and accumulation in soil, water or sediment causing unexpected long-term effects on living organisms. The regulatory P-criteria must ensure that this concern does not materialise, with a sufficient margin of safety.

This was explored for a reference temperature of $20{ }^{\circ} \mathrm{C}$ assuming realistic worst case soil/climate/crop scenarios in the EU developed by EFSA [18]. The average annual air temperature for the scenarios relevant to total soil in the Northern, Central and Southern European Zone is $4.7,8.0$ and $11.0{ }^{\circ} \mathrm{C}$, respectively. A PPP with a half-life of 120 days at $20{ }^{\circ} \mathrm{C}$ was assumed to be applied at each location to a winter cereal crop every year for 20 years, or every 3 years for 45 years. Triennial application is common for PPP as these are often specific to certain agricultural crops, and these crops are grown in a rotation with other crops which are treated with different products. Concentrations of the PPP in soil were calculated using the FOCUS model PELMO [32], an exposure model that is well accepted in the regulatory framework [27] and which considers extrapolation of the degradation rate constants to the respective temperature values in the soil on a daily basis. The scenario parameterisation for this model is provided by EFSA [20]. The climate conditions reflect actual conditions over multiple years at the scenario sites and change throughout the simulation period in order to account for the natural variability between different years at the same location. Figure 1 shows that the rate of decline in concentrations after application differs between the various years, and even within a single year as a result of the temporal variation in the climate. The calculations were continued for a number of years after the last application.

Figure 1 (upper panel) shows that the maximum and minimum simulated total concentration in soil reached just after an application initially increases year-on-year, because there is some residual chemical left from the previous application the year before. It is a mathematical consequence of first-order degradation that the minimum and maximum concentrations stabilise at a certain level over time, if the frequency and magnitude of the emission remain constant. The levels, and the time at which stabilisation occurs, depend on the half-life and the actual environmental conditions. Figure 1 (upper panel) shows the pattern of concentrations that can be expected for realistic worst case soil/climate/crop scenarios in the EU based on the half-life of 120 days in soil at $20^{\circ} \mathrm{C}$, considering the temporal and spatial variability. The build-up of concentrations in soil stabilises after 6,8 and 10 years in the Southern, Central and Northern zone, respectively. Thus, there is a range of $8 \pm 2$ years, i.e. the variability in the time after which the plateau is reached in the three zones is $25 \%$ (coefficient of variation, CV). The simulated minimum residues before the next application stabilise at around $6 \mathrm{mg} / \mathrm{kg}$ soil in the Southern climate zone, $10 \mathrm{mg} /$ $\mathrm{kg}$ soil in the Central zone and $16 \mathrm{mg} / \mathrm{kg}$ in the Northern zone, this corresponds to a CV of $47 \%$. The $\mathrm{CV}$ of the simulated maximum concentrations (approximately 13, 20 and $27 \mathrm{mg} / \mathrm{kg}$ soil in the three climate zones) is $35 \%$. These CVs reflect the spatial variability between the three zones.

The results in Fig. 1 (lower panel) show that the residues stabilise at much smaller levels if an application is only made every 3 years. Moreover, Fig. 1 (lower panel) shows that there is a negligible increase of the plateau over time after triennial application in all zones from year 2 . The substance is only present for a relatively short time 

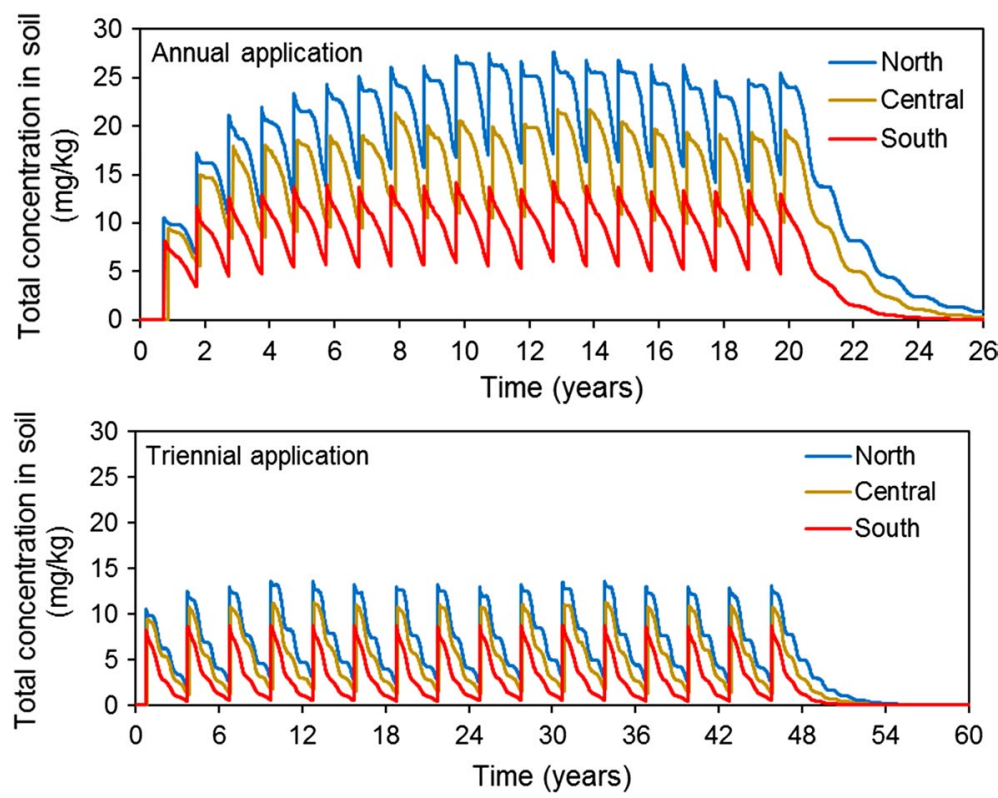

Fig. 1 Concentration of a PPP with a half-life of 120 days at $20^{\circ} \mathrm{C}$ in soil calculated for the EFSA soil scenarios in the Northern, Central and Southern Regulatory Zones $[18,20]$ for annual (top panel) and triennial application (bottom panel)

after the last release; the concentrations in soil decline steadily to negligible levels within a few years.

Additional calculations were undertaken for a hypothetical compound discharged to EU surface waters (Fig. 2). The chemical has a half-life for fresh water of 40 days and for sediment of 120 days at $20{ }^{\circ} \mathrm{C}$. The
FOCUS surface water model TOXSWA was used to calculate the mass of the chemical in water and sediment of a pond and a ditch for two of the FOCUS locations with annual average temperatures of 12.1 and $16.7^{\circ} \mathrm{C}$ [29]. The model adjusts the half-life to the actual daily temperature of the scenario. The chemical was discharged into the


Fig. 2 Mass of a PPP with a half-life of 40 days in water and 120 days in sediment at $20^{\circ} \mathrm{C}$ calculated for the FOCUS surface water scenarios La Jailliere (top panels) and Thiva (bottom panels) for water (left panels) and sediment (right panels) 
water once a year for 10 years with variable climate conditions. Figure 2 shows that even in a static pond there is no long-term increase of the annual maximum mass in the water, very limited increase in the sediment over the 10 years and the chemical disappears within a few years of the last emission.

\section{Experimental temperature to determine degradation half-lives}

The purpose of simulation degradation testing in the context of the P-classification is to determine a half-life for comparison with the persistence criteria defined by the EU regulations. In principle, tests could be undertaken at any temperature within the ranges given in the test guidelines and the resulting half-lives could be adjusted to other temperatures using correction procedures. However, this extrapolation carries some uncertainties. It is therefore advantageous to undertake the test at the actual temperature of interest $\left(20{ }^{\circ} \mathrm{C}\right.$ is appropriate for the P-criterion) and avoid the need for extrapolation. There are additional advantages of a test temperature of $20{ }^{\circ} \mathrm{C}$ and these are discussed below.

\section{Practical considerations and comparability with existing data}

Historically, degradation tests for PPP regulatory purposes have been undertaken at $20{ }^{\circ} \mathrm{C}$, with few studies at $10{ }^{\circ} \mathrm{C}$. This is partly for practical reasons. There is a much wider availability of laboratory test facilities to study degradation at $20{ }^{\circ} \mathrm{C}$ than at lower temperatures, less risk of study temperatures to deviate from the target, and the costs are reduced. There is now a large database of experimental half-lives at $20{ }^{\circ} \mathrm{C}$ (e.g. The University of Hertfordshire Pesticide Properties Database, http:// sitem.herts.ac.uk/aeru/ppdb/en/index.htm). This allows benchmarking of results for new chemicals against the existing data.

\section{Uncertainties in the half-lives}

Half-lives are derived by fitting kinetic models to chemical residues plotted against time. The FOCUS work group on degradation kinetics [28] gives guidance on how to undertake the model fitting. The group stressed that the data set must be of sufficient quality to clearly establish the dissipation pattern. It is difficult to obtain robust kinetic fits to data that decline slowly over time. In these cases, the confidence intervals of the estimated degradation rate constants are often large, indicating parameter uncertainty. This is because there is not enough information inherent in the data to obtain a reliable estimate of degradation. At low temperatures, the study period is simply too short to give a sufficient decline in the residues beyond the half-life. A test temperature of $20^{\circ} \mathrm{C}$ causes a faster decline of the residues and allows a more reliable kinetic analysis. This is illustrated in Fig. 3 using hypothetical data. The graph shows an example fit of first-order kinetics to the mass of a chemical measured at 10 and $20{ }^{\circ} \mathrm{C}$. The $95 \%$ confidence interval of the half-life at $10^{\circ} \mathrm{C}$ is $99-242$ days, this is much wider than the confidence interval at $20^{\circ} \mathrm{C}$ of $50-75$ days.

For a robust assessment of the degradation rate constant, the residues should ideally decline to $10 \%$ by the end of the study, but at least reach the half-life (i.e. $50 \%$ of initial mass or less). The typical study period of 120 days is long enough to reach the half-life in soil of non-persistent substances at a test temperature of $20^{\circ} \mathrm{C}$. If $12{ }^{\circ} \mathrm{C}$ or even $9{ }^{\circ} \mathrm{C}$ was used as the reference temperature for the P-criterion, then the P-criterion for soil would have to be much longer. The experimental period could be extended, but this might lead to an undesirable loss of biological activity and additional costs. It is thus much more straightforward to discriminate between persistent and non-persistent substances at a test temperature of $20^{\circ} \mathrm{C}$. Uncertainties in the optimisation could lead to an under-estimation of the half-life and this could result in an incorrect classification of a substance as non-persistent when it is in fact persistent, or vice versa. Where a geometric mean or other form of average is calculated from several half-lives of the same substance, it is important that the individual estimates are accurate because the uncertainty of each estimate is propagated into a greater uncertainty of the average. As it is easier to obtain robust half-lives at $20^{\circ} \mathrm{C}$, this is the preferred experimental temperature.

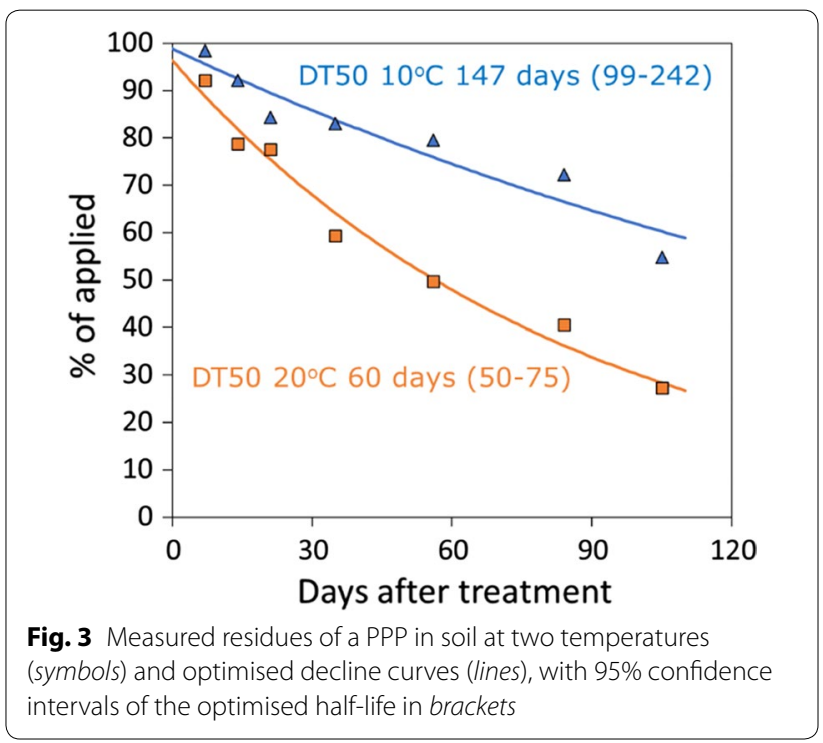




\section{Identification and quantification of metabolites}

At higher temperatures, metabolites are formed at larger quantities and earlier in the study period. Breakdown products that are classified as major metabolites at $20^{\circ} \mathrm{C}$ may not be detected at all at $10{ }^{\circ} \mathrm{C}$. Deriving robust halflives for metabolites at $10{ }^{\circ} \mathrm{C}$ will often be impossible. Performing the test at $20^{\circ} \mathrm{C}$ will avoid having to carry out two experiments, one to derive the half-life of the parent compound and one to detect and identify metabolites. This will not only save experimental effort, but also time for kinetic analysis and reporting, regulatory evaluation and decision making.

\section{Extrapolation to other temperatures}

The relationship between the degradation rate constant and temperature is often described by the Arrhenius or similar equations [19]. The Arrhenius equation assumes that the first-order rate constant of degradation depends on the activation energy $E_{a}$ of the reaction and the temperature at which the reaction occurs.

$$
k=A \exp ^{-\left(\frac{E a}{R T}\right)} .
$$

$k=$ degradation rate constant $\left[\mathrm{d}^{-1}\right] . A=$ factor equal to the rate coefficient at infinite temperature

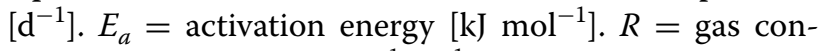
stant $=0.008314\left[\mathrm{~kJ} \mathrm{~mol}^{-1} \mathrm{~K}^{-1}\right]$ and $T=$ absolute temperature $[\mathrm{K}]$.

The degradation half-life is related to the degradation rate constant by $\ln (2) / k$. The experimental half-life can be extrapolated to the temperature of interest using this relationship:

$$
t_{1 / 2}(T \text { ref })=t_{1 / 2}(T) \exp ^{\left(\frac{E a}{R}\left[\frac{1}{T r e f}-\frac{1}{T}\right]\right)}
$$

$t \frac{1}{2}(T)=$ half-life at experimental temperature $T$ [days] and $t \frac{1}{2}($ Tref $)=$ half-life at temperature of interest Tref [days].

The equations could in principle be used to adjust a half-life measured at $20{ }^{\circ} \mathrm{C}$ in a degradation simulation test to a half-life at any other temperature, for example $12{ }^{\circ} \mathrm{C}$. ECHA $[15,16]$ guidance recommends a simplified version of the equation shown here to correct from the experimental temperature to $12^{\circ} \mathrm{C}$ :

$$
t_{1 / 2}\left(12{ }^{\circ} \mathrm{C}\right)=t_{1 / 2}\left(T^{\circ} \mathrm{C}\right) \exp ^{\left(0.08\left[T^{\circ} \mathrm{C}-12^{\circ} \mathrm{C}\right]\right)} .
$$

The validity of the Arrhenius equation has been discussed extensively. It is based on the concept that a certain amount of energy (i.e. the activation energy) is needed for a chemical reaction to occur. In surface waters, sediment and soils, chemical breakdown is mediated by a number of different reactions, including cleavage of molecules by enzymes released by microorganisms, photolytic and hydrolytic reactions. These reactions will not all have the same activation energy. Microbial transformations further depend on the abundance and activity of micro-organisms and the stability of enzymes which are also related to temperature. The temperature at which micro-organism is most active can vary from species to species.

The composition of the microbial population is not the same in all surface waters, sediments and soils. The potential for microbial degradation of chemicals will, therefore, also vary between biological systems. The interesting question is: even if the various systems have a different absolute level of microbial activity, is the relative change of this activity as a result of changing temperature the same in all systems? This question can be split into two aspects: (i) is the shape of the temperature response (linear, exponential, etc.) the same in all systems, i.e. can the same type of equation be used to describe this response, and (ii) are the parameters of the response curve the same in all systems? In the context of this opinion paper, this translates to the following: (i) is the Arrhenius equation valid in all systems, and (ii) is the activation energy the same?

For PPP, there is a wealth of experience with the use of the Arrhenius equation from the research and regulatory context. There is a large body of evidence that degradation in the field can be well predicted based on the Arrhenius equation if the difference in temperature between field and laboratory is taken into account. EFSA [19] collated a large number of degradation studies for PPP in soil conducted at different temperatures and fitted the Arrhenius equation to the half-lives. They concluded that the Arrhenius equation is valid over the temperature range from 0 to $30^{\circ} \mathrm{C}$. This was based on an analysis of 56 datasets. The frequency distribution of activation energies from 99 datasets had a median of $65.4 \mathrm{~kJ} \mathrm{~mol}^{-1}$. This activation energy was recommended by EFSA as a generic value for the temperature extrapolation within the exposure assessment for PPP. However, it was acknowledged that the activation energy for the temperature response of PPP degradation can vary from compound to compound. Variations in temperature response parameters have also been found by Bagi [4] for hydrocarbon biodegradation in marine environments. Alidina et al. [2] observed that the temperature response of chemical attenuation of trace organic chemicals in managed aquifer recharge systems depended on the compound.

In conclusion, there are uncertainties in the Arrhenius equation, and in the use of generic activation energy for all substances and media. It is therefore preferred to measure degradation at the temperature of interest. 
Where extrapolation is necessary, the option which introduces the least uncertainty into the decision making is preferred. For industrial chemicals and biocides, we have two options regarding the regulatory assessment: (i) measure the half-life at $20{ }^{\circ} \mathrm{C}$ and use this for comparison with the P-criterion, extrapolate to $12^{\circ} \mathrm{C}$ for the risk assessment, or (ii) measure at $12{ }^{\circ} \mathrm{C}$ and use this half-life in the risk assessment, extrapolate to $20{ }^{\circ} \mathrm{C}$ for comparison with the P-criterion. Option (i) would lead to a more accurate half-life for the persistence assessment. There would be some uncertainty in the risk assessment for industrial chemicals and biocidal products, but this uncertainty is overruled by the many other uncertainties inherently contained in exposure modelling. Moreover, the impact of degradation half-lives on exposure modelling outcome, i.e. PECs, is less relevant than for the P-assessment (see above). Option (ii) on the other hand places the uncertainty into the half-life used for comparison with the P-criterion. This has a much greater impact on the decision making particularly for PPP where the exceedance of the P-criteria could mean that there is no further assessment and the product cannot be registered. Therefore, on balance, it is preferred to measure at $20{ }^{\circ} \mathrm{C}$ and extrapolate to $12{ }^{\circ} \mathrm{C}$ if necessary. In the exposure assessment for PPP, an extrapolation is undertaken from the temperature at which the simulation tests are undertaken to the actual daily temperature in multi-year modelling scenarios for various European locations. Here, the uncertainty will be greater if the half-life is extrapolated to temperatures far above or below the reference temperature. A measurement temperature of $20^{\circ} \mathrm{C}$ appears to be a good compromise.

To our opinion, undertaking biodegradation tests at $20{ }^{\circ} \mathrm{C}$ and extrapolating to different environmental temperatures where necessary seems to be the best option, as long as the limitations of this approach are kept into consideration. Temperature should be systematically varied in laboratory incubation studies to better understand its impact on the biotransformations of chemicals.

\section{Conclusions}

There is a contentious issue in EU regulatory frameworks at which experimental temperature degradation simulation tests should be undertaken, and which temperature is relevant for comparison with persistence criteria. Two main alternatives are being considered: $20^{\circ} \mathrm{C}$ and a lower temperature (i.e. $9{ }^{\circ} \mathrm{C}$ for marine water and $12{ }^{\circ} \mathrm{C}$ for all other systems). There is a lot of experience gained from soil and water/sediment simulation tests conducted at $20{ }^{\circ} \mathrm{C}$ (or room temperature), in particular for PPP, but only few data from testing at lower temperatures. This opinion comes to the conclusion that measuring degradation at $20{ }^{\circ} \mathrm{C}$ has several advantages over lower temperatures in the light of accuracy and uncertainty as well as the regulatory purpose:

(1) Concentrations of metabolites/transformation products are higher and thus are identified with higher accuracy.

(2) Robust kinetic fits of dissipation processes are better achieved for higher temperature with less uncertainty.

(3) Comparison of degradation half-lives with $\mathrm{P} / \mathrm{vP}$ criteria at $20{ }^{\circ} \mathrm{C}$ is in line with the intentions of some international agreements on PBT chemicals and POPs. Scenario calculations for PPP with halflives of 120 days at $20{ }^{\circ} \mathrm{C}$ in soil and sediment, and of 40 days in water, adjusted to various European climate zones, demonstrate the expected concentration patterns. But the relevant temperature for comparison with persistence criteria is a regulatory question that needs a broad evaluation of the possible solutions and their relative advantages and disadvantages, based on scientific background and political intentions of the regulatory frameworks.

(4) Uncertainty of persistence classification is smallest when measured degradation half-lives are used for direct comparison with $\mathrm{P} / \mathrm{vP}$ assessment criteria.

(5) Extrapolation of half-lives to lower temperatures using the Arrhenius equation is justified for assessing exposure to industrial chemicals and biocidal products in a standard European environment as well as for comparing degradation of PPP in different European climate zones as long as the limitations of this approach are kept into consideration.

(6) Additional systematic laboratory studies focusing on the temperature range below $20^{\circ} \mathrm{C}$ in soils, and water-sediment systems for a range of contaminant classes would enhance our understanding of the impact of environmental temperature variation on the biotransformations of chemicals.

\section{Abbreviations}

B: bioaccumulative; $\mathrm{BCF}$ : bioconcentration factor; $\mathrm{CV}$ : coefficient of variation; DT50: time for 50\% dissipation or disappearance; FOCUS: Forum for International Co-ordination of pesticide fate models and their Use; ISO: International Standards Organization; LRT: long-range transport; OECD: Organisation for Economic Cooperation and Development; OSPAR: Oslo Paris Convention; PEC: predicted environmental concentration; P: persistent; PNEC: predicted no-effect concentration; PBT: persistent, bioaccumulative, and toxic; POP: persistent organic pollutant; $P_{\text {ov: }}$ overall persistence in all compartments; PPP: plant protection product; (Q)SAR: (quantitative) structure-activity-relationship; REACH: Registration, Evaluation, Authorization and Restriction of Chemicals; T: toxic; $t_{1 / 2}$ : half-life; TGD: Technical Guidance Document; UNEP: United Nations Environment Program; vB: very bioaccumulative; $v P$ : very persistent.

\section{Authors' contributions}

The authors MM and SB contributed equally to the ideas and writing of the paper. MM formatted and prepared the paper for submission. Both authors read and approved the final manuscript. 


\section{Author details}

${ }^{1}$ Institute of Environmental Systems Research (USF), University of Osnabrück, 49069 Osnabrück, Germany. ${ }^{2}$ Enviresearch Ltd, 34 Grainger Park Road, Newcastle upon Tyne NE4 8RY, UK.

\section{Acknowledgements}

Not applicable.

\section{Competing interests}

Funding for this assessment was provided by BASF (Germany). The opinions expressed in this paper are those of the authors alone and the authors declare no competing financial or non-financial interests.

Received: 26 April 2016 Accepted: 14 March 2017

Published online: 05 April 2017

\section{References}

1. Abelkop ADK, Graham JD, Royer TV (2015) Persistent, bioaccumulative, and toxic (PBT) chemicals: technical aspects, policies, and practices. CRC Press, Boca Raton

2. Alidina M, Shewchuk J, Drewes JE (2015) Effect of temperaure on the removal of trace organic chemicals in managed aquifer recharge systems. Chemosphere 122:23-31

3. Arnot J, Gouin T, Mackay D (2005) Development and application of models of chemical fate in Canada: practical methods for estimating environmental biodegradation rates. CEMN Report No. 200503, Canadian Environmental Modelling Network, Trent University, Peterborough, Canada, http://www.trentu.ca/academic/aminss/envmodel/CEMNReport200503.pdf

4. Bagi A (2013) Effect of low temperature on hydrocarbon biodegradation in marine environments. Ph.D. thesis no. 199, University of Stavanger, Norway, ISBN: 978-82-7644-539-8, ISSN: 1890-1387

5. Beyer A, Wania F, Gouin T, Mackay D, Matthies M (2003) Temperature dependence of the characteristic travel distance. Environ Sci Technol 37:766-771

6. Boethling RS, Howard PH, Meyian W, Stiteler W, Beauman J, Tiradot M (1994) Group contribution method for predicting probability and rate of aerobic biodegradation. Environ Sci Technol 28:459-465

7. Boethling R, Fenner K, Howard P, Klecka G, Madsen T, Snape JR, Whelan MJ (2009) Environmental persistence of organic pollutants: guidance for development and review of POP risk profiles. Integr Environ Assess Manag. 5:539-556

8. CEPA (1999) Canadian Environmental Protection Act, 255

9. CNG (2000) Non-hazardous products-proposals for implementation of new guidelines on chemicals policy, technical report SOU 2000:53. Swedish Committee on New Guidelines on Chemical Policy, Stockholm

10. DG SANCO (2012) Working Document on "Evidence needed to identify POP, PBT and vPvB Properties for Pesticides", Brussels, 25 Sept 2012-rev. 3, European Commission, Health and Consumers Directorate-General, Safety of the Food chain, Chemicals, contaminants, pesticides. http:// ec.europa.eu/food/plant/pesticides/approval_active_substances/docs/ wd_evidence_needed_to_identify_pop_pbt_vpvb_properties_rev3_ en.pdf. Accessed 18 March 2016

11. DG SANCO (2013) Ad hoc study to support the initial establishment of the list of candidates for substitution as required in Article 80(7) of Regulation (EC) No 1107/2009. Final Report. Brussels, 09 July 2013. European Commission Directorate General for Health and Consumers. http://ec.europa.eu/food/plant/docs/pesticides_ppp_app-proc_cfs_ report-201307.pdf. Accessed 05 Oct 2016

12. ECHA (2008) Guidance on information requirements and chemical safety assessment. Chapter R.11: PBT Assessment, May 2008, European Chemicals Agency, Helsinki. http://www.reach-info.de/dokumente/information_requirements_r11.pdf

13. ECHA (2012) Guidance on information requirements and chemical safety assessment. Chapter R1 1: PBT/vPvB Assessment. Version 1.2, Technical Report ECHA-12-G-07-EN. European Chemicals Agency, Helsinki

14. ECHA (2012) Guidance on Information Requirements and Chemical Safety Assessment. Chapter R.16: Environmental Exposure Assessment.
Version 2, Technical Report ECHA-10-G-06-EN. European Chemicals Agency, Helsinki

15. ECHA (2014) Guidance on Information Requirements and Chemical Safety Assessment. Chapter R.11: PBT/vPvB Assessment. Version 2, Technical Report ECHA-14-G-07-EN. European Chemicals Agency, Helsinki

16. ECHA (2016) Guidance for Information Requirements and Chemical Safety Assessment. Chapter R.7b: Endpoint specific guidance. Draft version 4.0 (Public). European Chemicals Agency, Helsinki

17. ECHA (2016) Guidance on Information Requirements and Chemical Safety Assessment. Chapter R.11: PBT/vPvB Assessment. Draft version 4.0 (Public). European Chemicals Agency, Helsinki

18. EFSA (2010) Selection of scenarios for exposure of soil organisms to plant protection products. EFSA J 8(6):1642

19. EFSA (2007) Scientific opinion of the panel on plant protection products and their residues on a request from EFSA related to the default Q10 value used to describe the temperature effect on transformation rates of pesticides in soil. EFSA J 622:1-32

20. EFSA (2012) Tier-1 and Tier-2A scenario parameterisation and example calculations. EFSA J 10(1):2433

21 EMA (2014) Guidance on the assessment of persistent, bioaccumulative and toxic (PBT) or very persistent and very bioaccumulative ( $\mathrm{PPVB}$ ) substances in veterinary medicine. European Medicines Agency, London. Rapport nr. EMA/CVMP/ERA/52740/2012; 2012. http://www.ema.europa. eu/docs/en_GB/document_library/Scientific guideline/2012/07/ WC500130368.pdf

22 Environment Canada (1995) Toxic substances management policypersistence and bioaccumulation criteria final report of the ad hoc science Group on criteria Technical Report En40-499/1-1995, Environment Canada, Ottawa

23 EP\&C (2006) Regulation (EC) No 1907/2006 of the European Parliament and of the Council of 18 December 2006 concerning the registration, evaluation, authorisation and restriction of chemicals (REACH), establishing a European chemicals agency, amending directive 1999/45/ EC and repealing Council Regulation (EEC) No 793/93 and Commission Regulation (EC) No 1488/94 as well as Council Directive 76/769/EEC and Commission Directives 91/155/EEC, 93/67/EEC, 93/105/EC and 2000/21/ EC. Off J Eur Commun, L 396/1

24 EP\&C (2009) Regulation (EC) No 1107/2009 of the European Parliament and of the Council of 21 October 2009 concerning the placing of plant protection products on the market and repealing council directives 79/117/EEC and 91/414/EEC (91/414/EEC). Off J Europ Commun. 52:1-50

25 EP\&C (2012) Regulation (EU) No 528/2012 of the European Parliament and of the Council of 22 May 2012 concerning the making available on the market and use of biocidal products. Off J Eur Commun 1-123

26 European Commission (2003) Technical Guidance Document on Risk Assessment in Support of Commission Directive 93/67/EEC on risk assessment for new notified substances part II. Commission Regulation (EC) No 1488/94 on risk assessment for existing substances and of directive 98/8/EC of the European Parliament and of the Council concerning the placing of biocidal products on the market, Technical Report EUR 20418 EN/2 Luxembourg

27 European Commission (2014) Assessing potential for movement of active substances and their metabolites to ground water in the EU. Report of the FOCUS ground water work Group, EC Document Reference Sanco/13144/2010 version 3

28 FOCUS (2014) Forum for international co-ordination of pesticide fate models and their use. Generic guidance for estimating persistence and degradation kinetics from environmental fate studies on pesticides in EU registration. Version 1.1. http://esdac.jrc.ec.europa.eu/projects/degradation-kinetics. Accessed April 2016

29 FOCUS (2015) Forum for International Co-ordination of pesticide fate models and their use. Generic guidance for surface water scenarios (version 1.4) http://esdac.jrc.ec.europa.eu/projects/surface-water. Accessed April 2016

30 Honti M, Fenner K (2015) Deriving persistence indicators from regulatory water-sediment studies - opportunities and limitation in OECD 308 data. Environ Sci Technol 49:5879-5886

31 IJC (1989) International Joint Commission. Revised Great Lakes water quality agreement of 1978 (as amended by Protocol signed November 18,1987), Technical Report NA, Windsor. 
32 Klein M (1995) PELMO Pesticide leaching model, user manual version 2.01. Fraunhofer Institute for Molecular Biology and Applied Ecology IME, Schmallenberg

33 Matthies M, Klasmeier J, Beyer A, Ehling C (2009) Assessing persistence and long-range transport potential of current-use pesticides. Environ Sci Technol 43:9223-9229

34 Matthies M, Solomon K, Vighi M, Gilman A, Tarazona J (2016) The origin and evolution of assessment criteria for persistent, bioaccumulative and toxic (PBT) chemicals and persistent organic pollutants (POPs). Environ Sci Process Impacts. 18:1114-1128

35 METI (2017) Chemical Substances Control Law, Ministry of Economy, Trade and Industry, Government of Japan. http://www.meti.go.jp/english/information/data/chemical_substances01.html. Accessed March 2017

36 Moermond C, Janssen M, de Knecht J, Montforts M, Peijnenburg W, Zweers P, Sijm D (2011) PBT assessment using the revised Annex XIII of REACH—a comparison with other regulatory frameworks. Integr Environ Assess Manag. 8:359-371

37 OECD (2002a) Aerobic and Anaerobic Transformation in Soil. OECD Guidelines for the Testing of Chemicals Nr. 307. Paris; 2002. http://www. oecd-ilibrary.org/environment/test-no-307-aerobic-and-anaerobic-transformation-in-soil9789264070509-en. Accessed 08 April 2014

38 OECD (2002b) Test No. 308: Aerobic and anaerobic transformation in aquatic sediment systems-simulation biodegradation test, guidelines for the testing of chemicals, Section 3. Paris, France: OECD. Report 308. http://www.oecd-ilibrary.org/content/book/9789264070523-en. Accessed 24 April 2002

39 OECD (2004) Test No. 309: Aerobic mineralisation in surface watersimulation biodegradation test, Guidelines for the testing of chemicals, Section 3. Paris, OECD. Report 307. http://www.oecd-ilibrary.org/content/ book/9789264070547-en. Accessed 24 April 2002

40 OSPAR (2001) Oslo Paris convention for the protection of the marine environment of the North-East Atlantic. Guidance on how to apply the safety net procedure for the inclusion of substances in the list of substances of possible concern, Technical. OSPAR Commission, London

41 OSPAR (2003) Oslo Paris convention for the protection of the marine environment of the North-East Atlantic. Hazardous substances strategy, technical. OSPAR Commission, London

42 Rauert C, Friesen A, Hermann G, Jöhncke U, Kehrer A, Neumann M, Prutz I, Schönfeld J, Wiemann A, Willhaus K, Wöltjen J, Duquesne S (2014) Proposal for a harmonised PBT identification across different regulatory frameworks. Environ Sci Eur 26:9
43 Scheringer M, MacLeod M, Matthies M, Klasmeier J, Witt J (2006) Persistence criteria in the REACH legislation: critical evaluation and recommendations. German Environmental Agency, Dessau. http://www.reach-info. de/dokumente/gutachten_gesamtpersistenz.pdf

44 Scheringer M, Jones KC, Matthies M, Simonich S, van de Meent D (2009) Multimedia partitioning, overall persistence, and long-range transport potential in the context of POPs and PBT chemical assessments. Integr Environ Assess Manag 5:557-576

45 Sinkkonen S, Paasivirta J (2000) Degradation half-life times of PCDDs, PCDFs and PCBs for environmental fate modeling. Chemosphere 40:943-949

46 Solomon KR, Matthies M, Vighi M (2013) Assessment of PBTs in the EU: a critical assessment of the proposed evaluation scheme with reference to plant protection products. Environ Sci Eur 25:1-25

47 UNECE (1998) Protocol to the 1979 convention on long-range transboundary air pollution on persistent organic pollutants. Technical United Nations Economic Commission for Europe, Geneva

48 UNEP (1999) Meeting documents related to the negotiations of the Stockholm Convention. 2nd meeting of the POPs Criteria Expert Group, Vienna, Austria, 14-18 June 1999. http://chm.pops.int/TheConvention/ Overview/History/Documents/tabid/62/Default.aspx

49 UNEP (2001) Stockholm convention on persistent organic pollutants. Technical, Secretariat of the Stockholm Convention, Geneva

50 USEPA (1978) Great Lakes water quality agreement. Annex 12. Persistent toxic substances., United States Environmental Protection Agency. http:// www.epa.gov/grtlakes/glwqa/1978/annex.html\#ANNEX\%2012. Accessed 22 Jan 2015

51 USEPA (1998) Proposed category for persistent, bioaccumulative, and toxic chemical substances. Fed Reg 63:53417-53423

52 USEPA (1998b) Fate, transport and transformation test guidelines: OPPTS 835.3300 soil biodegradation. United States Environmental Protection Agency. Prevention, Pesticides and Toxic Substances (7101). EPA712-C-98-088, January 1998. http://www.regulations. gov/\#!documentDetail;D=EPA-HQ-OPPT-2009-0152-0025

53 USEPA (1999) Category for persistent, bioaccumulative, and toxic new chemical substances. Fed Reg 64:20194-60204

54 USEPA (2012) Estimation Programs Interface Suite ${ }^{\mathrm{TM}}$ for Microsoft $\left.{ }^{(}\right)$ Windows, v 4.11. United States Environmental Protection Agency, Washington

\section{Submit your manuscript to a SpringerOpen ${ }^{\circ}$ journal and benefit from:}

- Convenient online submission

- Rigorous peer review

- Immediate publication on acceptance

- Open access: articles freely available online

- High visibility within the field

- Retaining the copyright to your article

Submit your next manuscript at springeropen.com 